\title{
Detection, causes and consequences of convection currents in bulk-stored grain
}

\author{
C.B.S. UISO', M.C. GOUGH ${ }^{2} \&$ C. J. STIGTER ${ }^{3}$ \\ 1 Physics Department, University of Dar es Salaam, Tanzania \\ 2 Industrial Development Department, Overseas Development Natural Resources Institute, \\ Slough, Berkshire SL3 7HL, UK \\ 3 TTMI-Project, c/o Department of Meteorology, Wageningen Agricultural University, \\ Duivendaal 2, NL 6701 AP Wageningen, Netherlands
}

Received 2 September 1989, accepted 15 March 1990

\begin{abstract}
A simple theoretical model was derived to predict velocities of intergranular cyclic air convection currents in bulk stored grain for a given temperature difference between outer and inner vertical regions of the bulk. Using a tracer gas, the measured airflow in a laboratory simulation was found to be in good agreement with theoretical predictions for differences in the range 17 to $25^{\circ} \mathrm{C}$. In tropical field trials in a metal silo, weather-induced intergranular air convection was, for the first time, detected and quantified in practical bulk storage. Significant moisture content increases, proven here to be due to convective air transported moisture, were observed in the top of the grain bulk in laboratory and field experiments. In both cases, troublesome head space condensation occurred. One new way is recommended for reducing observed grain damage due to moisture and the scope for future academic work has been indicated.
\end{abstract}

Keywords: grain storage, intergranular air convection, ultra-low airflow measuring techniques, bulk grain moisture migration, grain damage prevention

\section{Introduction}

Many tropical regions have very conducive climates for the development of conditions which can cause deterioration of stored grain (e.g. Stephenson, 1978). Accumulation of moisture is one of the main reasons for stored grain damage, and air currents due to convection were hypothesized to be the main cause of moisture migration in tall tropical structures (Caro \& Pfost, 1974; Stewart, 1975). The objectives of this study were:

- to demonstrate, for the first time experimentally by direct detection, the existence of intergranular natural convective airflow in bulk stored grain due to (virtual) temperature differences,

- to determine the magnitude of the airflow velocities,

- to field-test ultra-low airflow, moisture content and temperature measuring equipment, 
- to observe the physical changes in stored grain induced in the detected ways by weather and climate and to recommend ways to minimize these changes.

The study was performed in a laboratory simulation experiment in Slough (UK) and in two field trials with maize stored in bulk in a 250 tonne capacity steel silo in an upland near-equatorial climate with high diurnal temperature amplitudes in Njombe, Tanzania.

\section{Materials and methods}

After having shown that the general theory for convective air movement leads to equations that can not be solved for our experimental conditions without many more additional quantitative experiments, a simple theoretical model of convective airflow was derived, in line with earlier work (e.g. Bakker-Arkema et al., 1969). The equation concerned is:

$$
V=C(\Delta P / L)^{n}
$$

where:

$V=$ convective air velocity at the narrowest part of the airflow circuit

$\Delta P=$ pressure difference caused by (virtual) temperature differences

$L=$ total effective length of grain path for the flowing air

$C, n=$ constants characteristic of the cereal (and packing) concerned

A laboratory experiment was set up to test the validity of the model. The apparatus consisted of two vertical interconnected cylindrical columns of different diameter and temperature filled with shelled maize, simulating portions of a narrow cold grain layer near a silo wall and a larger warm central bulk. Convective airflow in this closed rectangular circuit was measured with an SF6 tracer gas technique. Quantification of the concentration of the tracer was made by electrochromatography based on electron capture detection. Other details of this experiment can be found in Gough et al. (1987).

In the field trials in the silo, ultra-low moisture migrating convective flows were hypothesized to be caused by diurnal ambient temperature patterns. These flows were detected and quantified by three different techniques: SF6 again, with a special gas sampling set specifically designed and constructed for these field trials; a differential pressure technique, using an electrical micromanometer based on detection of capacitance changes induced by bending of a diaphragm due to the pressure differences; and a bubble flow technique, using movements of a detergent film along a glass tube as an indicator of pressure differences. In this way these methods were thoroughly field-tested. The bubble flow technique had an accuracy of $0.2 \times 10^{-4} \mathrm{~m} \mathrm{~s}^{-1}$ and was the only one that could be used below $2.0 \times 10^{-4} \mathrm{~m} \mathrm{~s}^{-1}$, with a lower limit of $0.7 \times 10^{-4} \mathrm{~m} \mathrm{~s}^{-1}$, below which also this method became less accurate. The other two methods had an accuracy of $0.4 \times 10^{-4} \mathrm{~m} \mathrm{~s}^{-1}$ and the SF6 technique became rapidly unreliable below $2.5 \times 10^{-4} \mathrm{~m} \mathrm{~s}^{-1}$ and the pressure difference technique below $2.0 \times 10^{-4} \mathrm{~m} \mathrm{~s}^{-1}$ (see also Table 1). Thermistors and 
Table 1. Predawn convective air flow range in $10^{-4} \mathrm{~m} \mathrm{~s}^{-1}$, upward and downward at $1.5 \mathrm{~m}$ below grain top surface at different distances from the silo wall, measured with different techniques.

\begin{tabular}{|c|c|c|c|c|}
\hline \multirow{2}{*}{$\begin{array}{l}\text { Direction of } \\
\text { air flow }\end{array}$} & \multirow{2}{*}{$\begin{array}{l}\text { Distance from } \\
\text { silo wall }\end{array}$} & \multicolumn{3}{|c|}{ Measuring technique } \\
\hline & & $\begin{array}{l}\text { SF6 } \\
\text { technique }\end{array}$ & $\begin{array}{l}\text { differential } \\
\text { pressure } \\
\text { technique }\end{array}$ & $\begin{array}{l}\text { bubble } \\
\text { flow } \\
\text { technique }\end{array}$ \\
\hline Downward & Near shaded wall & $1.9-3.7$ & $0.7-2.8$ & $1.3-2.2$ \\
\hline Downward & $0.1 \mathrm{~m}$ from shaded wall & 1.4-1.9 & $0.3-2.0$ & 1.4 \\
\hline Upward & At the silo axis & $0.8-1.0$ & $0.2-2.2$ & $1.5-1.7$ \\
\hline
\end{tabular}

Reethorpes, remote moisture sensors based on measuring electrical resistance of grain between cylindrical electrodes (Gough, 1980), were used for temperature and moisture measurements, respectively, in these trials. Physical changes in the stored grain (Gough, 1985) were also observed.

\section{Results and discussion}

In the laboratory the detected intergranular convective airflows ranged from $1.7 \times 10^{-4}$ to $5.2 \times 10^{-4} \mathrm{~m} \mathrm{~s}^{-1}$ and were found to be proportional to the temperature difference between the columns. They were in good agreement with the theoretical predictions in the range between 17 and $25^{\circ} \mathrm{C}$. At a lower temperature difference and for moisture transport predictions, the model was less successful. Moisture content increases higher than calculated were observed at the top region of the cold grain column, which was attributed to moisture translocation from the warm grain by the convection mechanism. More quantitative results can be found in Gough et al. (1987).

In the field trials, grain temperature and moisture profiles were mapped over time in the top $1.5 \mathrm{~m}$ of grain. Significant diurnal temperature changes, with a maximum range near the shaded wall at $1.5 \mathrm{~m}$ below grain top surface (g.t.s.) of between 15 and $17{ }^{\circ} \mathrm{C}$, were observed to be confined to within $0.4 \mathrm{~m}$ from the grain surface. Surface temperature of the grain followed closely ambient temperature variations, with a maximum range near the silo axis at g.t.s. of between 14 and $17{ }^{\circ} \mathrm{C}$. Relatively strong downward convective airflow was detected at predawn in the cold grain near the silo walls. The flow magnitudes at $1.5 \mathrm{~m}$ below g.t.s. (Table 1; storage period ranges covered were not identical for the different techniques) were of the same order of magnitude as in the laboratory experiments. As expected, a relatively weak predawn upward flow was detected in the warm central bulk at the same depth, increasing an order of magnitude in the course of the storage period (Table 1). The flow directions, as measured at the shaded side of the silo, were reversed during hot afternoons. The measurements to a depth of $1.5 \mathrm{~m}$ below grain top surface indicated that the flow was monocyclic. These results confirmed for the first time by direct experiment the existence of natural convective airflow in practical bulk grain storage. The identical order of magnitude strongly suggests that the same primary 


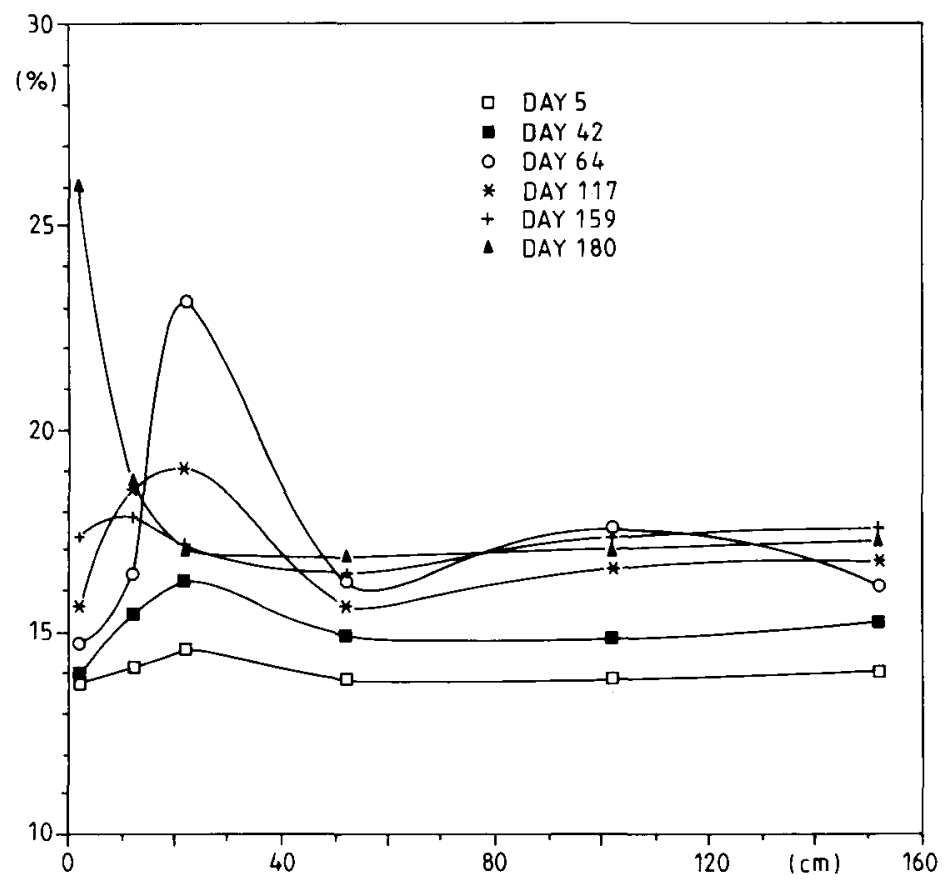

Fig. 1. Grain moisture content (in percentage) profiles along the silo central axis during the second field trial (October 1983-May 1984) as a function of distance from grain top surface (g.t.s.) in cm. Moisture increase is on the average higher in the first $0.5 \mathrm{~m}$ near g.t.s.

causes identified in the laboratory model, that is induced (virtual) temperature gradients, are at work. These field results demonstrated the potential suitability of the tested equipment for measuring ultra-low airflows, although appreciable experimental difficulties remained under the harsh field conditions encountered in the silo head space.

Appreciable grain moisture increases occurred in the whole bulk, be it much more near the top surface, during the first field trial, due to poor initial storage conditions and the related metabolic processes. During the second trial, large moisture build-up occurred especially near the grain top surface (Fig. 1) and along the silo walls in the top region (for example, ranging from as low as $12.5 \%$ (on day 26) to as high as nearly $21 \%$ (on day 180 ) at the eastside at $1.5 \mathrm{~m}$ below g.t.s.), resulting in mould growth in these areas. This was largely due to condensation and (towards the end) internal raining of condensed water, occurring on the inner surface of the silo walls at headspace level and on the underside of the silo roof. Condensation and internal raining were a consequence of the effects of ambient weather and convective air flows in the silo. These air flows were themselves clearly due to a combination of temperature and moisture gradients with complicated but recognizable patterns in space and time.

Empirical recommendations to reduce air convection and moisture build-up in 
bulk-stored grain under our tropical conditions, like proper pre-storage grain drying and cooling, aeration or regular grain turning, silo wall insulation or use of concrete and the use of broader instead of tall structures, can now be better selected with the understanding we collected on the (onset of) hazardous convection currents and better be planned from our quantitative approach. A suggestion of natural daytime headspace ventilation to prevent moisture build-up may be added from our research. In the suggested scope for future academic work figure: more rigorous theoretical models of different aspects of convective flow in a porous medium of this kind, improved and validated flow measuring techniques, and more attention to traditional storage structures, of which even less is known.

\section{Acknowledgements}

The University of Dar es Salaam, the UN-University, the Storage Department of the former Tropical Development Research Institute (now ODNRI) and the Dutch government (DGIS) funded former Direction of Agricultural Physics (DAP) Project in Dar es Salaam are acknowledged for financial contributions to these studies. We thank The Tanganyika Wattle Company Ltd. for its collaboration in using its facilities and its grain in Njombe, Tanzania.

\section{References}

Bakker-Arkema, F. W., R. J. Patterson \& W. G. Bickert, 1969. Static pressure-airflow relationschips in packed beds of granular biological material such as cherry pits. Transactions of the American Society of Agricultural Engineers 12: 134-136, 140.

Caro, A. \& H. B. Pfost, 1974. Moisture absorption of bulk stored grain under tropical conditions. Research Report No. 6. Food and Feed Grain Institute, Kansas State University, Manhattan, Kansas.

Gough, M. C., 1980. Evaluation of a remote moisture sensor for bulk grain. Journal of Agricultural Engineering Research 25: 29-37.

Gough, M. C., 1985. Physical changes in large-scale hermetic grain storage. Journal of Agricultural Engineering Research 31: 55-65.

Gough, M. C., C.B.S. Uiso \& C. J. Stigter, 1987. Convection currents in bulk grain. Tropical Science 27: $29-37$.

Stephenson, K. Q., 1978. Seed storage for tropical climates. American Society of Agricultural Engineers Paper No. 78-4519.

Stewart, J. A., 1975. Moisture migration during storage of preserved, high moisture grains. Transactions of the American Society of Agricultural Engineers 18: 387-393, 400.

This synopsis is based on a Ph.D. thesis 'Convection currents in bulk stored grain: detection, causes and consequences' by C.B.S. Uiso, Physics Department, University of Dar es Salaam, Tanzania, 1989, 290 pp., 30 tables, 75 figs., 129 refs., 2 apps, in English. Available as paper copy (order R104, $f$ 40,- including postage, free for developing countries) at: NARD, c/o Pudoc, P.O. Box 4, 6700 AA Wageningen (telex 45015 bluwg nl). 